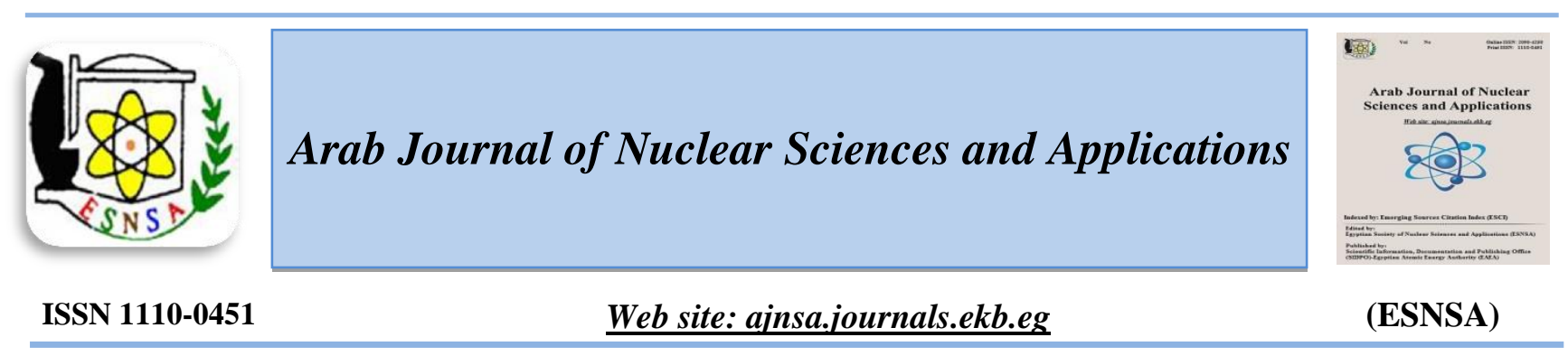

\title{
Impact of Oocyte Morphology on Fertilization, Embryo Quality and Pregnancy after ICSI: Evaluation with Diabetes and PCOS
}

\author{
N.A. Abu-Elnaga ${ }^{(1)}$, A.B. Mehaney ${ }^{(2)}$, H.M.G. Youssef ${ }^{(3)}$, S.M. Mahmoud ${ }^{(4)}$, A.S. Salim ${ }^{(1)}$

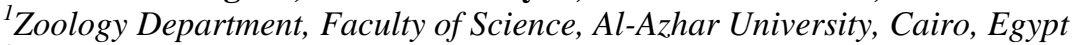 \\ ${ }^{2}$ EmbryologyInternational Islamic Center for Population Studies and Research, Al-Azhar University, \\ Cairo, Egypt \\ ${ }^{3}$ Health Radiation Research Department, National Center for Radiation Research and Technology (NCRRT), \\ Egyptian Atomic Energy Authority, Cairo, Egypt \\ ${ }^{4}$ Obstetrics \& Gynecology, International Islamic Center for Population Studies and Research, Al-Azhar University, \\ Cairo, Egypt
}

Received $3^{\text {rd }}$ Apr. 2019 Accepted $15^{\text {th }}$ May 2019

\begin{abstract}
Intra-cytoplasmic sperm injection (ICSI) has become an essential procedure in assisted reproductive units for infertile patients. Polycystic ovary syndrome (PCOS) and diabetes are two syndromes having drawbacks on fertility. The aim of this research is to study the impact of the morphological abnormalities of MII oocytes on fertilization rate, embryo quality and pregnancy following ICSI in patients with diabetes, PCOS patients. This prospective observational study was conducted on 177 women. MII oocytes with normal or abnormal morphology, fertilization rate, embryo quality, and positive or negative pregnancies were assessed in all patients and compared between the different groups. In the control group the total number of oocyte abnormalities was 146/446 MII oocytes representing a percentage of $(33 \%)$. In the diabetes group, the total number of abnormalities in MII oocytes was 231/90 MII oocytes representing a percentage of (257\%), and in the PCOS group, the total number of abnormalities was 414/229 abnormalities in the MII oocytes representing a percentage of $(\mathbf{1 8 1 \%})$. In the diabetic patients, despite the higher oocytes abnormalities and the lower quality embryos compared to the PCOS patients, the pregnancy rate was significantly higher in the diabetes group $(59.5 \%)$ compared to the PCOS group $(51.9 \%)$, the highest percentage of pregnancy presented in the control group $(83.7 \%)$. ICSI outcome was significantly better in the diabetic patients when compared to the PCOS patients. The best outcome was observed in the control group..
\end{abstract}

Keywords: ICSI, Diabetes, PCOS, Oocytes dysmorphology

\section{Introduction}

Intra cytoplasmic sperm injection (ICSI) needs assessment of both the oocyte morphology and the exact stage of their maturation. Coordination in nuclear and cytoplasmic maturation is needed to supply an ideal oocyte [1] which has a clear cytoplasm, a single polar body (PB), an appropriate zona pellucida (ZP) thickness and a proper perivitelline space (PVS) [2]. However, after controlled ovarian hyperstimulation in ICSI, many of the retrieved oocytes have one or more abnormalities [3]. It is important to predict oocyte quality for better selection criteria before fertilization with subsequent selection from the developed embryos before embryo transfer $[4,5]$. The most frequently observed oocytes morphologic variations are cytoplasmic changes, including granularity, darkness and vacuole presence. Extracytoplasmic dysmorphology is present in oocyte shape, ZP, PVS, and PB [6]. Some researchers have reported that MII oocyte morphology had a minor impact on the fertilization

Corresponding author: hanangabr62@gmail.com

DOI: 10.21608/ajnsa.2019.10225.1184

(C) Scientific Information, Documentation and Publishing Office (SIDPO)-EAEA 
rate and embryo quality in women with normal ovarian response [7]. Others have correlated between the oocyte quality, the fertilization rate, the embryo development and the ICSI outcomes.

It was reported that determining pregnancy potential at the oocyte level rather than the embryo level might provide an insight into the embryo selection for transfer. A previous Study suggested the oocyte scoring as a cheaper method than closed incubation systems with time-lapse photography [8]. Another research had focused on the embryo quality as the best for pregnancy chances, and had concentrated on improving embryo rather than oocyte assessment, which leads to increasing the cost as the closed automated incubation systems with time-lapse photography [9].

Women with diabetes mellitus often show low quality oocytes, increased chances of miscarriage, and congenital malformations of offspring $[10,11]$. The developmental anomalies during distinct stages induced by maternal diabetes have been reported; and even a brief exposure to diabetic state in periconceptual period has lasting effects on the embryonic development $[12,13]$. Hyperglycemia induced a downregulation of the facilitative glucose transporters at the blastocyst stage, which resulted in a decreased glucose uptake and thus lowered intraembryonic free glucose levels [14], and proved to be sufficient to induce apoptosis at blastocyst stage [15]. Glucose is a necessary energy substrate for oocyte maturation $[16,17]$.

Patients with PCOS are characterized by the production of large number of oocytes during stimulation, but poor-quality oocytes and embryos, lower fertilization, cleavage and implantation rates, and higher miscarriage rates. Although scientists identified many extra-ovarian and intra-ovarian factors that cause irregularities during folliculogeneis, follicular growth and oocyte maturation yet remain a challenge to explain the underlying molecular mechanisms in PCOS [18].

With the use of time-lapse technology, assessment of the kinetic development of embryos explored that embryos of PCOS developed slower from fertilization to the 8-cell stage than embryos from controls [19]. Detection of the time to pronuclear fading with cumulus cell apoptosis by time-lapse microscope are considered as independent prognostic factors of chemical pregnancy, clinical pregnancy, and live birth [20].

Researchers reported that PCOS patients had more available oocytes in ICSI cycles, the fertilization rate was significantly higher than in controls; and the embryo arrest rate was not correlated with testosterone level [21]. The present study is designed to compare the morphological abnormalities of oocytes resulting after controlled ovarian hyperstimulation in diabetes and PCOS groups with their impact on fertilization rates, quality of embryos and pregnancy outcome after ICSI.

\section{Patients and Methods}

This prospective case control study was done on 191 women, 14 patients did not complete the study, and thus the study was conducted on 177 women. The control group consisted of 86 selected women with good ovarian response. The PCOS group consisted of 62 women, 54 patients of them completed the study while 8 patients left, meanwhile the diabetic group consisted of 43 patients, 6 women left while 37 women completed the study. The patients were recruited from the International Islamic Center for Population Studies and Research, Assisted Reproductive Unit, AlAzhar University, Cairo, Egypt. The study stated from January until December 2018.This research study was allowed in accordance with the ethical standards of the Assisted Reproductive Unit, and was approved by the ethical committee of (NCRRT). The study was conducted in accordance with the Helsinki Declaration and all participants gave informed consent before their inclusion in this study. All patients who had ovarian stimulation with the long protocol and had been referred to intracytoplasmic sperm injection (ICSI) were screened for selecting the patients who were eligible for inclusion. The subjects recruited were classified into 3 groups:

1-Control group: consisted from 86 women selected to be (age matched, normal ovarian response, and neither PCOS nor diabetics). From them 72 became pregnant and 14 failed to become pregnant.

2-Diabetes group: consisted from 37 women diagnosed as diabetics and controlled by hypoglycemic drugs, 15 women had failed pregnancy and 22 women had positive pregnancy. 
3-PCOS group: consisted from 54 women with PCOS, 26 women had failed pregnancy and 28 women had positive pregnancy. According to the Rotterdam Consensus Criteria (ASRM/ESHRE Consensus Working Group on PCOS, 2004), the diagnosis of PCOS was based on the presence of at least two of the three following criteria: oligomenorrhea/amenorrhea, hyperandrogenemia and/or hyperandrogenism and polycystic ovaries on ultrasound.

Each group was subdivided into 2 subgroups according to occurrence of pregnancy.

The inclusion criteria for patients were the age from 25 to 38 years, infertility was either primary or secondary, fair ovulation response to induction, normal quality of sperms of their husbands, and these cycles for the patients were their first trials of ICSI. The exclusion criteria were patients older than 38 years, poor responders diagnosed as having less than four dominant follicles on the day of HCG administration and or less than four oocytes retrieved, a peak $E_{2}$ level of $<500 \mathrm{pg} / \mathrm{ml}$ or a history of one cancelled IVF cycle due to poor response and lastly the male factor of infertility. Medical history had been taken from each patient with the diagnosis, duration of infertility, number of previous pregnancies, and associated diseases and their therapy, with initial examination of semen analysis of the husband. Transvaginal ultrasound, hysterosalpingogram or sonohysterogram, or hysteroscopy was conducted for each patient for evaluation of the state of the ovaries, uterus, and patency of the tubes.

Withdrawal of venous blood from patients for assay of (FSH, LH, PRL, TSH and E2), the liver function tests (AST, ALT, total protein, Albumin, both total and direct bilirubin), kidney function tests (Urea, Creatinine), random glucose level, and analysis of hemoglobin level, hematocrite, RBC, WBC and Platelets count were all done. All subjects received the GnRH long protocol consisted of a depot injection of therapeutic dose triptorelin (Decapeptyl $3.75 \mathrm{mg}$ ) on day 21 of the preceding cycle, after 14 days, the down-regulation status was assessed. Patients were considered responding when endometrial thickness reached $7 \mathrm{~mm}$ or serum E2 was $<50 \mathrm{pg} / \mathrm{ml}$, progesterone level was $<0.5 \mathrm{ng} / \mathrm{ml}$. Following down-regulation confirmation, the gonadotrophin was administered in a dose of 75-300 IU/ml/day adjusted according to ovarian volume, ovarian activity, presence or absence of (PCOS), the patient's age, previous response to ovarian stimulation, baseline serum FSH concentrations on day 2 or 3 of menstruation, ovarian reserve. Follow-up of the ovarian response every 2-3 days was performed by vaginal ultrasound. In normal responders, ovulation was triggered by administration of HCG (10,000 IU) I.M. when at least 4 follicles reached $18 \mathrm{~mm}$. Oocytes retrieval were done 36 hours after hCG injection by the digital needle guide, and using falcon tissue culture dish and 4 well embryo culture dishes to collect oocytes covered with cumulus masses. Oocyte was identified in horizontal laminar flow hood with Olympus stereo microscope, the oocyte was clearly visible. Oocytes were denudated from cumulus oophorus by exposure to $80 \mathrm{IU} / \mathrm{ml}$ hyaluronidase enzyme in HEPES-buffered medium followed by mechanical removal of the corona radiata. Oocytes were assessed for their maturation and morphology under an inverted microscope.

Good-quality mature human oocytes have a clear, moderately granular, homogeneous cytoplasm that does not contain inclusions; a small PVS; a round clear, colorless ZP and single unfragmented PB [4, 22]. Dysmorphic oocytes are commonly classified as having abnormal cytoplasm (dark cytoplasm, not homogenous or increased granularity), cytoplasmic inclusions (vacuoles, refractile bodies), an abnormal oocyte shape (oval), an abnormal ZP, an abnormal PVS), and an abnormal $\mathrm{PB}[4,22]$. Injected oocytes were examined for integrity and fertilization about 16-18 hours after ICSI. Oocytes were considered normally fertilized when evaluating the presence of two pronuclei (2PN) and the extrusion of the second PB. The fertilization rate after ICSI was usually expressed per number of injected oocytes. Post-fertilization, about $90 \%$ of 2-PN oocytes obtained by ICSI enter cleavage, result in multicellular embryos. After 48 hours, embryos that had cleaved to the two or four cell-stage, then 2-3 embryos from the best quality for each patient were transferred to the uterus. Patients performed a serum beta HCG titre15 \pm 2 days after oocyte collection for determination of pregnancy.

\section{Statistical Analysis}

All Analyses were performed using the Statistical Package for the Social Science version 20 for Windows (SPSS 20Inc, Chicago, IL) and $p$ value $<0.05$ was significant. Quantitative variables were described as means \pm SD and by summation 
and percentages. Summation of all oocytes types, morphological abnormalities and their percentages in relation to MII oocytes were conducted. A comparison between groups was performed by one-way ANOVA. Nominal data were analyzed using Chi-square test.

\section{Results}

Table (1) clarified that the cause of infertility in the diabetic and PCOS group was due to ovulation problems; meanwhile the cause of infertility in the control group was tubal and uterine factors.
In table (2) FSH ampoules needed for controlled ovarian hyperstimulation is significantly the highest in diabetes with estrogen peak is the lowest in diabetes group; day of oocytes pickup is significantly higher in diabetes compared to PCOS and control groups. It is clear that diabetics need more FSH ampoules and more days of stimulation

Table (1): A comparison between the studied groups as regards the cause of infertility

\begin{tabular}{cccc}
\hline Cause of infertility & Control group & Diabetes group & PCOS group \\
\hline Tubal factor & $45 / 86$ & 0 & 0 \\
Ovulation problem & 0 & $37 / 37$ & $54 / 54$ \\
Uterine factor & $16 / 86$ & 0 & 0 \\
Endometriosis & 0 & 0 & 0 \\
Unexplained infertility & $25 / 86$ & 0 & 0 \\
\hline
\end{tabular}

Table (2): A comparison between the studied groups as regards the patients' characteristics, hormonal and blood analysis using Oneway-ANOVA

\begin{tabular}{llllll}
\hline Parameter & Control group & Diabetes group & PCOS group & F & Significance \\
\hline Age & $28.9 \pm 3.5$ & $31.2 \pm 3.1$ & $29.1 \pm 3.6$ & 5.48 & $.05^{*}$ \\
BMI & $28.84 \pm 2.6$ & $28.1 \pm 1.7$ & $28.2 \pm 5.8$ & .607 & .54 \\
Infertility duration & $4.1 \pm 1.2$ & $4.5 \pm 1.1$ & $5.3 \pm 1.6$ & 12.1 & $.01^{*}$ \\
FSH & $5.9 \pm 0.6$ & $5.2 \pm 0.9$ & $5.8 \pm 1.1$ & 11.3 & $.01^{*}$ \\
LH & $4.0 \pm 1.3$ & $4.1 \pm 1.5$ & $4.5 \pm 1.4$ & 1.6 & .20 \\
Prolactin & $18.4 \pm 4.5$ & $17.4 \pm 1.7$ & $18.7 \pm 3.8$ & 1.4 & .24 \\
E2 & $42.7 \pm 2.7$ & $44.8 \pm 2.6$ & $40.8 \pm 5.2$ & 12.7 & $.01^{*}$ \\
FSH amp. & $3.60 \pm 1.0$ & $5.54 \pm 0.60$ & $3.09 \pm 1.12$ & 74.24 & $.000^{*}$ \\
Day of pickup & $12.42 \pm 0.71$ & $14.73 \pm 3.0$ & $12.07 \pm 1.30$ & 32.95 & $.00^{*}$ \\
Estrogen peak & $2503.4 \pm 318.3$ & $2371.2 \pm 385.2$ & $2679.9 \pm 694.9$ & 4.6 & $.01^{*}$ \\
TSH & $2.12 \pm 0.7$ & $2.9 \pm 0.6$ & $2.6 \pm 0.9$ & 14.7 & $.01^{*}$ \\
Hemoglobin & $12.7 \pm 0.4$ & $12.3 \pm 0.5$ & $12.0 \pm 0.6$ & 7.5 & $.01^{*}$ \\
RBCs & $4.4 \pm 0.9$ & $4.6 \pm 0.4$ & $4.6 \pm 0.5$ & 2.2 & .10 \\
WBCs & $6.7 \pm 1.6$ & $8.5 \pm 1.3$ & $6.8 \pm 1.9$ & 14.5 & $.00^{*}$ \\
PLTs & $313.1 \pm 48.8$ & $310.5 \pm 43.1$ & $339.8 \pm 43.4$ & 6.5 & $.00^{*}$ \\
Random B. glucose & $89.8 \pm 11.3$ & $419.8 \pm 50.8$ & $96.2 \pm 9.1$ & 2298.1 & $.000^{*}$ \\
urea & $22.8 \pm 2.8$ & $22.7 \pm 3.5$ & $23.5 \pm 3.5$ & 1.13 & .32 \\
Creatinine & $0.83 \pm 0.08$ & $0.83 \pm 0.09$ & $0.85 \pm 0.07$ & 1.01 & .36 \\
ALT & $15.5 \pm 4.8$ & $18.3 \pm 11.0$ & $14.8 \pm 5.7$ & 2.96 & $.05^{*}$ \\
AST & $17.8 \pm 4.5$ & $20.3 \pm 8.1$ & $18.7 \pm 4.9$ & 2.32 & .10 \\
Albumin & $5.0 \pm 0.46$ & $5.5 \pm 0.65$ & $4.6 \pm 0.21$ & .479 & .62 \\
\hline
\end{tabular}


Table (3): A comparison of MII oocytes morphological abnormalities, fertilization rate, high grade and low-grade embryos between negative pregnancy patients $(n=55)$ and positive pregnancy patients $(n=122)$ in the study sample $(n=177)$

\begin{tabular}{lllll}
\hline Parameter & $\begin{array}{l}\text { Negative } \\
\text { pregnancy } \\
=55 \text { patients }\end{array}$ & $\begin{array}{l}\text { Percentage } \\
\text { (\% from MII) }\end{array}$ & $\begin{array}{l}\text { Positive } \\
\text { pregnancy }=122 \\
\text { patients }\end{array}$ & $\begin{array}{l}\text { Percentage } \\
\text { (\% from MII) }\end{array}$ \\
\hline MII & $\mathbf{1 5 4}$ & & $\mathbf{6 1 1}$ & \\
Corona Radiata & 27 & $17.5 \%$ & 12 & $2 \%$ \\
Oolema Abnormal & 67 & $43.5 \%$ & 14 & $2.3 \%$ \\
Perivitelline Space & 78 & $50.6 \%$ & 91 & $14.9 \%$ \\
Zona Pellucida & 76 & $49.4 \%$ & 82 & $13.4 \%$ \\
Polar Body & 74 & $48 \%$ & 44 & $7.2 \%$ \\
Vacuoles & 18 & $11.7 \%$ & 0 & 0 \\
Cytoplasm. Abnormal & 82 & $53.2 \%$ & 42 & $7 \%$ \\
Shape Abnormal & 69 & $44.8 \%$ & 15 & $2.5 \%$ \\
Fertilization rate & 140 & $90.9 \%$ & 595 & $97.3 \%$ \\
High grade Embryo & 50 & $32.5 \%$ & 542 & $88.7 \%$ \\
Low grade Embryo & 90 & $58.4 \%$ & 53 & $8.6 \%$ \\
Sum. \& percent. of MII & $491 / 154$ & $\mathbf{3 1 8 . 7 \%}$ & $300 / 611$ & $\mathbf{4 9 . 3 \%}$ \\
abnormalities & & & & \\
\hline
\end{tabular}

Table (4): A correlation between abnormalities in oocytes, with fertilization, high quality embryos, low quality embryos

\begin{tabular}{|c|c|c|c|}
\hline Pearson correlation of & Fertilization rate & High quality embryo & Low quality embryo \\
\hline Polar body & $-.383-^{* *}$ & $-.453-^{* * *}$ & $.465^{* *}$ \\
\hline p-value & .000 & .000 & .000 \\
\hline Zona pellucida & $-.229-^{* *}$ & $-.304-^{* *}$ & $.423^{* *}$ \\
\hline p-value & .002 & .000 & .000 \\
\hline Perivitelline space & $-.237-^{* *}$ & $-.373-^{* *}$ & $.440^{* *}$ \\
\hline $\mathrm{p}$-value & .000 & .000 & .000 \\
\hline Oocyte Shape & $-.443-^{* *}$ & $-.509-^{* *}$ & $.456^{* *}$ \\
\hline p-value & .000 & .000 & .000 \\
\hline Cytoplasm abnormality & $-.481-^{* *}$ & $-.595-^{* *}$ & $.580^{* * *}$ \\
\hline p-value & .000 & .000 & .000 \\
\hline Oolema & $-.505-^{* *}$ & $-.569-^{* *}$ & $.513^{* *}$ \\
\hline $\mathrm{p}$-value & .000 & .000 & .000 \\
\hline Corona radiata & $-.268-^{* *}$ & $-.328-^{* *}$ & $.323^{* *}$ \\
\hline p-value & .000 & .000 & .000 \\
\hline Vacuoles & $-.344-^{* *}$ & $-.410-^{* *}$ & $.370^{* *}$ \\
\hline p-value & .000 & .000 & .000 \\
\hline Fertilization rate & 1 & $.932 * *$ & $-.522-* *$ \\
\hline p-value & & .000 & .000 \\
\hline
\end{tabular}

Table (4) clarifies that PB, ZP, PVS, oocyte shape, cytoplasm, oolema, corona radiata, and vacuoles abnormalities are all inversely significantly correlated with fertilization rate and high-quality embryos, and positively significantly correlated with low quality embryos. 
Table (5): A comparison between the 6 subgroups classified according to occurrence of pregnancy using one way-ANOVA test

\begin{tabular}{|c|c|c|c|c|c|c|c|}
\hline $\begin{array}{l}\text { Subgroups according to } \\
\text { chemical pregnancy test }\end{array}$ & $\begin{array}{l}\text { Control } \\
\text { +ve preg. }\end{array}$ & $\begin{array}{l}\text { Control } \\
\text {-ve preg. }\end{array}$ & $\begin{array}{l}\text { Diabetes } \\
\text { +ve preg. }\end{array}$ & $\begin{array}{l}\text { Diabetes } \\
\text {-ve preg. }\end{array}$ & $\begin{array}{l}\text { PCOS } \\
\text { +ve preg. }\end{array}$ & $\begin{array}{l}\text { PCOS } \\
\text {-ve preg. }\end{array}$ & Significance \\
\hline Number of patients & $\mathrm{N}=72$ & $\mathrm{~N}=14$ & $\mathrm{~N}=22$ & $\mathrm{~N}=15$ & $\mathrm{~N}=28$ & $\mathrm{~N}=26$ & \\
\hline $\begin{array}{l}\text { Total no. of oocytes on U/S } \\
\text { (expected oocytes) }\end{array}$ & 576 & 91 & 155 & 115 & 353 & 393 & .000 \\
\hline Oocytes Retrieved & 495 & 72 & 93 & 110 & 244 & 130 & .000 \\
\hline $\begin{array}{l}\text { Number of MII oocytes } \\
\text { (\%from oocytes retrieved) }\end{array}$ & $396(80)$ & $50(70.8)$ & $56(60.2)$ & $34(30.9)$ & $159(65.1)$ & $70(53.8)$ & .000 \\
\hline $\begin{array}{c}\mathrm{N} \text { of MII/patient } \\
\text { Number of MI oocytes } \\
\text { (\%from oocytes retrieved) }\end{array}$ & $\begin{array}{c}5.5 \\
86(17.3)\end{array}$ & $\begin{array}{c}3.6 \\
18(25)\end{array}$ & $\begin{array}{c}2.55 \\
21(22.6)\end{array}$ & $\begin{array}{c}2.26 \\
15(13.6)\end{array}$ & $\begin{array}{c}5.67 \\
50(20.4)\end{array}$ & $\begin{array}{c}2.69 \\
25(19.2)\end{array}$ & .008 \\
\hline $\begin{array}{c}\text { Germinal vesicles } \\
\text { (\%from oocytes retrieved) }\end{array}$ & $11(2.2)$ & $3(4.1)$ & $9(9.6)$ & $10(9.0)$ & $25(10.2)$ & $6(4.6)$ & .000 \\
\hline $\begin{array}{l}\text { Number empty oocytes } \\
\text { (\%from oocytes retrieved) }\end{array}$ & $2(0.4)$ & $1(1.3)$ & $7(7.5)$ & $51(46.4)$ & $10(4.0)$ & $29(22.3)$ & .000 \\
\hline $\begin{array}{l}\text { Corona radiata } \\
\text { (\%per MII oocytes) }\end{array}$ & $\begin{array}{l}6 / 396 \\
(1.5)\end{array}$ & $\begin{array}{l}4 / 50 \\
(8)\end{array}$ & $\begin{array}{l}2 / 56 \\
(3.5)\end{array}$ & $\begin{array}{l}5 / 34 \\
(14.7)\end{array}$ & $\begin{array}{l}4 / 159 \\
(2.5)\end{array}$ & $\begin{array}{l}18 / 70 \\
(25.7)\end{array}$ & .000 \\
\hline $\begin{array}{l}\text { Zona Pellucida } \\
\text { (\%per MII oocytes) }\end{array}$ & $\begin{array}{c}30 / 396 \\
(7.5)\end{array}$ & $\begin{array}{c}15 / 50 \\
(30)\end{array}$ & $\begin{array}{l}11 / 56 \\
(19.6)\end{array}$ & $\begin{array}{l}27 / 34 \\
(79.4)\end{array}$ & $\begin{array}{r}41 / 159 \\
(25.7)\end{array}$ & $\begin{array}{l}34 / 70 \\
(48.5)\end{array}$ & .000 \\
\hline $\begin{array}{c}\text { Polar Body } \\
\text { (\%per MII oocytes) }\end{array}$ & $\begin{array}{l}22 / 396 \\
(5.5)\end{array}$ & $\begin{array}{l}10 / 50 \\
(20)\end{array}$ & $\begin{array}{c}8 / 56 \\
(14.2)\end{array}$ & $\begin{array}{l}29 / 34 \\
(85.2)\end{array}$ & $\begin{array}{c}14 / 159 \\
(8.8)\end{array}$ & $\begin{array}{c}35 / 70 \\
(50)\end{array}$ & .000 \\
\hline $\begin{array}{l}\text { Perivitelline space } \\
\text { (\%per MII oocytes) }\end{array}$ & $\begin{array}{c}28 / 396 \\
(7.0)\end{array}$ & $\begin{array}{c}14 / 50 \\
(28)\end{array}$ & $\begin{array}{l}12 / 56 \\
(21.4)\end{array}$ & $\begin{array}{l}25 / 34 \\
(73.5)\end{array}$ & $\begin{array}{c}51 / 159 \\
(31.4)\end{array}$ & $\begin{array}{l}39 / 70 \\
(55.7)\end{array}$ & .000 \\
\hline $\begin{array}{l}\text { Cytoplasm abnormality } \\
\text { (\%per MII oocytes) }\end{array}$ & $\begin{array}{c}6 / 396 \\
(1.5)\end{array}$ & $\begin{array}{l}5 / 50 \\
(10)\end{array}$ & $\begin{array}{l}12 / 56 \\
(21.4)\end{array}$ & $\begin{array}{l}27 / 34 \\
(79.4)\end{array}$ & $\begin{array}{c}24 / 159 \\
(15.0)\end{array}$ & $\begin{array}{l}50 / 70 \\
(71.4)\end{array}$ & .000 \\
\hline $\begin{array}{c}\text { Vacuoles } \\
\text { (\%per MII oocytes) }\end{array}$ & 0 & 0 & 0 & $\begin{array}{l}13 / 34 \\
(38.2)\end{array}$ & 0 & $\begin{array}{l}5 / 70 \\
(7.1)\end{array}$ & .000 \\
\hline $\begin{array}{l}\text { Oolema abnormality } \\
\text { (\%per MII oocytes) }\end{array}$ & 0 & $\begin{array}{l}3 / 50 \\
(6)\end{array}$ & $\begin{array}{c}6 / 56 \\
(10.7)\end{array}$ & $\begin{array}{l}25 / 34 \\
(73.5)\end{array}$ & $\begin{array}{c}8 / 159 \\
(5.0)\end{array}$ & $\begin{array}{l}39 / 70 \\
(55.7)\end{array}$ & .000 \\
\hline $\begin{array}{l}\text { Shape abnormality } \\
\text { (\%per MII oocytes) }\end{array}$ & 0 & $\begin{array}{l}3 / 50 \\
(6)\end{array}$ & $\begin{array}{l}4 / 56 \\
(7.1)\end{array}$ & $\begin{array}{l}25 / 34 \\
(73.5)\end{array}$ & $\begin{array}{c}11 / 159 \\
(6.9)\end{array}$ & $\begin{array}{l}41 / 70 \\
(58.5)\end{array}$ & .000 \\
\hline $\begin{array}{l}\text { Fertilization rate } \\
\text { (\% MII oocytes) }\end{array}$ & $\begin{array}{l}396 / 396 \\
(100)\end{array}$ & $\begin{array}{l}50 / 50 \\
(100)\end{array}$ & $\begin{array}{l}54 / 56 \\
(96.4)\end{array}$ & $\begin{array}{l}31 / 34 \\
(91.1)\end{array}$ & $\begin{array}{c}145 / 159 \\
(91.1)\end{array}$ & $\begin{array}{l}59 / 70 \\
(84.4)\end{array}$ & .000 \\
\hline $\begin{array}{l}\text { Cleavage rate at day } 3 \\
\text { (\% Fertilization })\end{array}$ & $\begin{array}{l}396 / 396 \\
(100)\end{array}$ & $\begin{array}{l}50 / 50 \\
(100)\end{array}$ & $\begin{array}{l}54 / 54 \\
(100)\end{array}$ & $\begin{array}{l}31 / 31 \\
(100)\end{array}$ & $\begin{array}{l}145 / 145 \\
(100)\end{array}$ & $\begin{array}{l}59 / 59 \\
(100)\end{array}$ & .000 \\
\hline $\begin{array}{l}\text { High quality embryo } \\
\text { (\% Fertilization) }\end{array}$ & $\begin{array}{c}385 / 396 \\
(97.2)\end{array}$ & $\begin{array}{c}33 / 50 \\
(66)\end{array}$ & $\begin{array}{l}48 / 54 \\
(88.8)\end{array}$ & 0 & $\begin{array}{c}109 / 145 \\
(75.2)\end{array}$ & $\begin{array}{l}17 / 59 \\
(28.8)\end{array}$ & .000 \\
\hline $\begin{array}{l}\text { Low quality embryo } \\
\text { (\% Fertilization) }\end{array}$ & $\begin{array}{c}11 / 396 \\
(2.8)\end{array}$ & $\begin{array}{c}17 / 50 \\
(34)\end{array}$ & $\begin{array}{c}6 / 54 \\
(11.1)\end{array}$ & $\begin{array}{l}31 / 31 \\
(100)\end{array}$ & $\begin{array}{c}36 / 145 \\
(24.8)\end{array}$ & $\begin{array}{l}42 / 59 \\
(71.2)\end{array}$ & .000 \\
\hline Pregnancy test & $\begin{array}{l}+\mathrm{ve} \\
83.7 \%\end{array}$ & $\begin{array}{l}-\mathrm{ve} \\
16.3 \%\end{array}$ & $\begin{array}{l}+\mathrm{ve} \\
59.5 \%\end{array}$ & $\begin{array}{l}\text {-ve } \\
40.5 \%\end{array}$ & $\begin{array}{l}+\mathrm{ve} \\
51.9 \%\end{array}$ & -ve $48.1 \%$ & .000 \\
\hline $\begin{array}{l}\text { Total number of abnormalities } \\
\text { in MII }\end{array}$ & $\begin{array}{l}92 / 396 \\
(23 \%)\end{array}$ & $\begin{array}{c}54 / 50 \\
(108 \%)\end{array}$ & $\begin{array}{l}55 / 56 \\
(98 \%)\end{array}$ & $\begin{array}{l}176 / 34 \\
(517 \%)\end{array}$ & $\begin{array}{c}153 / 159 \\
(96 \%)\end{array}$ & $\begin{array}{l}261 / 70 \\
(372 \%)\end{array}$ & .000 \\
\hline
\end{tabular}


A highly significant difference was noticed in the pregnancy rate in control $83.7 \%$, than in diabetes $59.5 \%$ and in PCOS 51.9\% groups using Pearson Chi square $=59.60$, Asym. Sign. $=0.000$. The current results clarify that presence of multiple abnormalities in the oocytes yields low quality embryos with no pregnancy in the ICSI cycles.

In spite of the fact that the resulted high-quality embryos per patient in PCOS group equals 2.33 embryos are more than in diabetes, in which the high-quality embryos equals 1.29 embryos, the percentage of positive pregnancy in diabetes group is higher than in PCOS group.

\section{Discussion}

Oocytes quality and its impact on fertilization rate, embryo development and the net outcome of ICSI cycles is a matter of debates. Some scientists reported oocyte morphology to be an important prognostic factor in successful treatment of ICSI cases, and a higher rate of ICSI failure in women with dysmorphic oocytes $[2,23]$. On the other hand, others reported that oocyte morphology does not correlate with fertilization rate and embryo quality after ICSI [24]. Rinzi et al, identified contradicting data about impact of morphological abnormalities of oocytes on ICSI, which recommended a further research [25].

In the present study, Table (2) shows that blood, hormonal profile, liver and kidney functions were within normal ranges, the random blood glucose were significantly higher in diabetics than the other two groups which needed optimum control with insulin during ICSI procedures. The number of retrieved oocytes from all subjects was 1144 , the number of MII was 765 (66.9\%) from retrieved oocytes, and the number of MIwas215 (18.8\%), the number of Germinal vesicles was $64(5 \%)$, the number of Empty oocytes was 100 (8.7\%). The fertilization rate in the control subjects was $100 \%$, in diabetes subjects was $96.4 \%$ in positive pregnant subgroup and $91.1 \%$ in negative pregnant subgroup, while in the PCOS group, the fertilization rate was $91.1 \%$ in positive pregnant subgroup and $84.4 \%$ in negative pregnant patients. Table (3) demonstrates that when comparing positive pregnancy patients with negative pregnancy patients in the whole sample (177), the dysmorphic MII oocytes percentage was $(49.3 \%)$ in positive pregnancy patients, while there was no ideal oocytes morphology (318.7\%) in all negative pregnancy patients, i.e over three abnormalities in each MII oocyte.

In negative pregnancies, the highest abnormality of MII oocytes was the cytoplasmic, then, PVS, $\mathrm{ZP}, \mathrm{PB}$, then abnormal shape, corona radiata and lastly the presence of vacuoles. However, in positive pregnancies, the higher abnormalities were PVS, ZP, then, the cytoplasmic and PB abnormalities in the same category then, oolema and oocytes shape. There were no vacuoles in all the MII oocytes that resulted in positive pregnancies. Highly significant differences were calculated in all morphological abnormalities between negative pregnancy patients and positive pregnancy patients with $p=0.000$.

The fertilization rate and the high-grade embryos were significantly higher in positive than negative pregnancy patients. Bilgic et al. found that both fragmented polar body and vacuole rates were significantly higher in cycles with grade 2 than grade 1 embryo transfer [26]. Setti et al. found that the presence of large PB, large PVS, vacuoles were correlated with decreased oocyte fertilization, but the effect of oocyte abnormalities on implantation and pregnancy rate remain unclear [4].

Consistent with the present results, researchers reported that identification of oocyte morphology might be a prognostic tool for embryo quality [6]. Similar with the obtained results were a study clarified that the fertilization rate was significantly lower in dysmorphic oocytes than in normal shaped oocytes, but inconsistent with the present results that embryo quality was similar in dysmorphic and normal form oocyte groups [22]. Bilgic et al. assessed the impact of oocyte morphological abnormality rates on embryo development and implantation, and stated that similar oocyte morphology abnormality rates were found between cycles with and without successful embryo implantation and concluded that none of oocyte morphological features was found to have significant impact on pregnancy outcome [26]. On the contrary, the current study revealed that the net outcome of positive pregnancy was higher in completely normal oocytes, and was less in dysmorphic oocytes which had one or more abnormalities. There were no vacuoles in positive pregnancy patients. However, only $1 \%$ abnormality was in corona radiata, $2 \%$ abnormality in oolema and shape, polar body and cytoplasmic abnormalities were of the same percentage (7\%). 
However, the highest percentage which seemed with no effect on the outcome pregnancy $(14 \%)$ stood for PVS and ZP abnormalities. Halim et al. in their research compared normal and oval shaped oocytes in ICSI and found $46.7 \%$ transferrable embryos in the oval oocytes group compared to $63.3 \%$ in the normal oocytes group. However, there was no significant difference in fertilization rates and embryo quality between normal morphology oocytes and oval-shaped oocytes, but with a higher percentage towards the normal shaped oocytes [27].

The highest number of MII oocytes/patients was in the control group with the highest fertilization rate and highest +ve pregnancy percentage. While in the PCOS group, the MII oocytes/patient and high-quality embryos were higher than in the diabetes group, the resulted +ve pregnancy percentage was higher in the diabetes group than in the PCOS group, perhaps in the PCOS, the hyperandrogenemia constitutes an obstacle for the occurrence of pregnancy which was not the case in diabetes.

In harmony with the obtained result, a previous study suggested that long standing hyperandrogenemia in the PCOS group, high luteinizing hormone level and insulin resistance might be the cause of compromised oocyte quality [28]. The fertilization rate was significantly different between groups. High quality embryos were the highest in the control group and significantly decreased in the PCOS and diabetes groups. The low-quality embryos were significantly higher in the diabetes group and the PCOS group than in the control group. When comparing the oocyte abnormalities percentage in MII oocytes in both the diabetes and PCOS groups with the control group, it was found that all oocytes abnormalities in the diabetes and PCOS negative and positive pregnancy subgroups are significantly higher than in the control subgroups. In a recent study, it was reported that the presence of granular vacuole in the oocyte cohort had no clinical impact except when transferred embryos were exclusively derived from dysmorphic oocytes [29]. Dysmorphic oocytes showed a significantly lower fertilization rate than normal form oocytes, but subsequent embryonic development and embryo quality was relatively good, and they defined specific abnormalities of oocytes related with top-quality embryos such as dark cytoplasm, abnormal PB, or vacuoles [22]. Researchers advised that evaluation of oocyte morphology with subsequent embryo morphokinetics was recommended in ART programs, by introducing the time lapse monitoring which could show that the cleavages of embryos were affected by the quality of MII oocytes. In their research there was a significant relation between oocyte morphology abnormalities and cleavage patterns, nearly all cleavage and interval times, except extrusion of second polar body time was similar between normal and abnormal morphologic oocytes [30].

\section{Conclusion}

In the control group, the oocytes dysmorphology are minimal, with highest fertilization rate, embryo quality and pregnancy rate. In the diabetes group, the oocyte abnormalities are higher compared to the PCOS group, but the pregnancy rate is higher in the diabetes group than in the PCOS group. It seems that the fertilization rate is not affected by the oocyte abnormalities as the embryo quality which is much affected by oocyte abnormalities. The pregnancy rate was significantly higher in the control group (83.7\%) than both the diabetic group $(59.5 \%)$ and the PCOS group (51.9\%). It could be concluded that ICSI outcome is significantly decreased in the PCOS group compared to the diabetes group.

\section{References}

1-Rienzi, L., Balaban, B., Ebner, T., Mandelbaum, J. (2012) The oocyte. Hum Reprod. 27:2-22.

2-Swain, J.E., Pool, T.B. (2008) ART failure: oocyte contributions to unsuccessful fertilization. Hum Reprod Update. 14:431-446.

3-Rienzi, L., Ubald, F.M., Iacobelli, M., Minasi, M.G., Romano, S., Ferrero, S. et al. (2008) Significance of metaphase II human oocyte morphology on ICSI outcome. Fertil Steril. 90:16921700 .

4-Setti, A.S., Figueira, R.C., Braga, D.P., Colturato, S.S., Iaconelli, A. Jr., Borges, E. Jr.(2011) Relationship between oocyte abnormal morphology and intracytoplasmic sperm injection outcomes: a meta-analysis. Eur J Obstet. Gynecol Reprod Biol. 159:364-370.

5-Cota, A., Oliveira, J., Petersen, C., Mauri, A., Massaro, F., Silva, L. et al. (2012) GnRH agonist versus GnRH antagonist in assisted reproduction cycles: oocyte morphology. Reprod Biol Endocrinol. 10:2-10.

6-Braga, D.P., Setti, A.S., Figueira, R., Machado, R.B., Iaconelli, A., Jr, Borges, E., Jr. (2013) Influence of oocyte dysmorphisms on blastocyst formation and quality. Fertil Steril. 100:748-754. 
7-Ashrafi, $\quad$ M., Karimian, L., Eftekhari-Yazdi, P., Hasani, F., Arabipoor, A., Bahmanabadi, A., et al. (2015) Effect of oocyte dysmorphisms on intracytoplasmic sperm injection cycle outcomes in normal ovarian responders. J ObstetGynecol Res. 41(12): 1912-20.

8-Lazzaroni-Tealdi, E., Barad, D.H., Albertini, D.F., Yu, Y., Kushnir, V.A., Russell, H., Wu, Y.G., Gleicher, N. (2015) Oocyte Scoring Enhances Embryo-Scoring in Predicting Pregnancy Chances with IVF Where It Counts Most. Plos One. 10:e0143632.

9-Herrero, J. and Meseguer, M . (2013) Selection of high potential embryos using time-lapse imaging: the era of morphokinetics. Fertility and Sterility. 99: 1030-1034.

10-Zhang, C.H., Qian, W.P., Qi, S.T., Ge, Z.J., Min, L.J., Zhu, X.L., et al. (2013) Maternal diabetes causes abnormal dynamic changes of endoplasmic reticulum during mouse oocyte maturation and early embryo development. J Reprod Biol Endocrinol. 11(1):31.

11-Vrachnis, N., Antonakopoulos, N., Iliodromiti, Z., Dafopoulos, K., Siristatidis, C., Pappa, K., et al. (2012) Impact of maternal diabetes on epigenetic modifications leading to diseases in the offspring. Exp Diabetes Res. 2012:538474.

12-Amaral, S., Oliveira, P.J., Ramalho-Santos, J. (2008) Diabetes and the impairment of reproductive function: possible role of mitochondria and reactive oxygen species. Curr Diabetes Rev. 4:46-54.

13-Jungheim, E.S., Moley, K.H. (2008) The impact of type 1 and type 2 diabetes mellitus on the oocyte and the preimplantation embryo. SeminReprod Med. 26:186-195.

14-Moley, K.H. (1999) Diabetes and preimplantation events of embryogenesis. Semin Reprod Endocrinol. 17:137-151.

15-Chi, M.M., Hoehn, A., Moley, K.H. (2002) Metabolic changes in the glucose-induced apoptotic blastocyst suggest alterations in mitochondrial physiology. Am J Physiol Endocrinol Metab. 283:226-232.

16-Preis, K.A., Seidel, G., Gardner, D.K. (2005) Metabolic markers of developmental competence for in vitro-matured mouse oocytes. Reproduction. 130:475-483.

17-Zheng, P., Vassena, R., Latham, K.E. (2007) Effects of in vitro oocyte maturation and embryo culture on the expression of glucose transporters, glucose metabolism and insulin signaling genes in rhesus monkey oocytes and preimplantation embryos. Mol Hum Reprod. 13:361-371.

18-Qiao, J., Feng, H.L. (2010) Extra- and intra-ovarian factors in polycystic ovary syndrome: impact on oocyte maturation and embryo developmental competence. Hum Reprod Update. 17:17-33.

19-Wissing, M., Bjerge, M., Olesen, A., Hoest, T., Mikkelsen, A. (2014) Impact of PCOS on early embryo cleavage kinetics. Reproductive Bio Medicine Online. 28: 508-514.

20-Tabibnejad, N., Aflatoonian, A., Motamedzadeh, L., Soleimani, M., Sadeghian-Nodoushan, F., Talebi, A. (2018) Assessing ICSI outcome by combining non-invasive indicators: Early time-lapse morphokinetics and apoptosis in associated cumulus cells among women with the polycystic ovarian syndrome. Mol Reprod Dev. 85:865-874.

21-Yin, B., Hao, H., Wei, D., Song, X., Xie, J., Zhang, C. (2015) Patients with polycystic ovary syndrome have successful embryo arrest. Int J Clin Exp Med. 8(4):6247-51.

22-Yu, E.J., Ahn, H., Lee, J.M., Jee, B.C., Kim, S.H. (2015) Fertilization and embryo quality of mature oocytes with specific morphological abnormalities. Clin Exp Reprod Med. 42:156-162.

23-Khalili, M.A., Sultan, A., Mojibian, M. (2005) Role of oocyte morphology on fertilization and embryo formation in assisted reproductive techniques. Middle East Fertil Soc J. 10:72-77.

24-De Sutter, P., Dozortsev, D., Qian, C., Dhont, M. (1996) Oocyte morphology does not correlate with fertilization rate and embryo quality after intracytoplasmic sperm injection. Hum. Reprod, 11:595-7.

25-Rienzi, L., Vajta, G., Ubaldi, F. (2011) Predictive value of oocyte morphology in human IVF: a systematic review of the literature. Hum Reprod Update. 17:34-45.

26-Bilgic, B., Yayla-Abide, C., Ozkaya, E., Kutlu, T., Ayla, S., Sanverdi, I. et al. (2018) Role of oocyte morphological abnormality rates on the embryo development and implantation. Gynecol Obstet Reprod Med. 24:131-138.

27-Halim, B., Lubis, H.P., Novia, D., Thaharuddin, M. (2017) Does oval oocyte have an impact on embryo development in in vitro fertilization? JBRA Assist Reprod. 21:15-18.

28-Kodama, H., Fukuda, J., Karube, H., Matsui, T., Shimizu, Y., Tanaka, T. (1995) High incidence of embryo transfer cancellations in patients with polycystic ovarian syndrome. Hum Reprod. 10:1962-7.

29-Sousa, M., Cunha, M., Silva, J., Oliveira, E., Pinho, M., Almeida, C. et al. (2016) Ultrastructural and cytogenetic analyses of mature human oocyte dysmorphisms with respect to clinical outcomes. $J$ Assist Reprod Genet. 33:1041-57.

30-Faramarzi, A., Khalili, M., Ashourzadeh, S. (2017) Oocyte morphology and embryo morphokinetics in an intra-cytoplasmic sperm injection program. Is there a relationship? Zygote. 25:190-196. 